\title{
BMJ Open Did psychotropic drug consumption increase during the 2008 financial crisis? A cross-sectional population-based study in Spain
}

\author{
Elena Arroyo,, ${ }^{1,2}$ Andrés Cabrera-León, ${ }^{2,3}$ Gemma Renart, ${ }^{1,2}$ Carme Saurina, ${ }^{2}$ \\ Laura Serra Saurina, ${ }^{1,2,4,5}$ Antonio Daponte, ${ }^{2,3,6}$ Marc Saez $^{1,2}$
}

To cite: Arroyo E, CabreraLeón A, Renart G, et al. Did psychotropic drug consumption increase during the 2008 financial crisis? A crosssectional population-based study in Spain. BMJ Open 2018;9:e021440. doi:10.1136/ bmjopen-2017-021440

\section{- Prepublication history and} additional material for this paper are available online. To view these files, please visit the journal online (http://dx.doi. org/10.1136/bmjopen-2018021440).

Received 2 January 2018 Revised 29 0ctober 2018 Accepted 20 November 2018

Check for updates

(C) Author(s) (or their employer(s)) 2018. Re-use permitted under CC BY-NC. No commercial re-use. See rights and permissions. Published by BMJ.

For numbered affiliations see end of article.

Correspondence to

Dr Marc Saez;

marc.saez@udg.edu

\section{ABSTRACT}

Objectives and setting Although psychotropic drugs are used to treat mental health disorders, little evidence analyses the effects the 2008 economic downturn had on psychotropic drug consumption in the case of Spain. We analyse these effects, considering both gender and employment situation.

Participants We used the microdata from the face-toface cross-sectional population-based Spanish National Health Survey for two periods: 2006-2007 ( $n=28954)$ and 2011-2012 $(n=20509)$. Our samples included adults ( $>15$ years old).

Methods The response variables are consumption (or not) of antidepressants or sedatives and the explanatory variables are the year of the survey, gender and employment status. Covariates are mental health problems, mental health index General Health Questionnaire (GHQ-12) and self-reported health outcome variables such as self-rated health, chronic diseases, smoking behaviour, sleeping hours, body mass index, physical activity in the workplace, medical visits during the past year, age, region of residence (autonomous communities), educational level, marital status and social class of the reference person. Finally, we include interactions between time period, gender and employment status. We specify random effects logistic regressions and use Bayesian methods for the inference.

Results The economic crisis did not significantly change the probability of taking antidepressant drugs $(\mathrm{OR}=0.56$, $95 \% \mathrm{Cl} 0.18$ to 2.56$)$ nor sedatives $(\mathrm{OR}=1.21,95 \% \mathrm{Cl}$ 0.26 to 5.49 ). In general, the probability of consuming antidepressants among men and women decreases, but there are differences depending on employment status. The probability of consuming sedatives also depends on the employment status.

Conclusions While the year of the financial crisis is not associated with the consumption of antidepressants nor sedatives, it has widened the gap in consumption differences between men and women. Although antidepressant use dropped, the difference in consumption levels between men and women grew significantly among the retired, and in the case of sedatives, risk of women taking sedatives increased in all groups except students.
Strengths and limitations of the study

- Microdata from the Spanish National Health Survey 2006-2007 and 2011-2012.

- Random effects logistic regressions so the intercept is different for the various levels considered.

- The Bayesian estimation provides greater flexibility (a consequence of its hierarchical strategy).

- We use penalising complexity priors. These priors are invariant to re-parameterisations and have robustness properties.

- The cross-sectional study design has difficulty in establishing a relationship between explanatory variables and outcomes.

\section{INTRODUCTION}

Since the Great Depression in 1930, concern about the effects of economic downturns on the health of a population has increased ${ }^{1-3}$ and while there are some controversial conclusions in the literature, most studies agree that mental health problems worsen during economic crises. ${ }^{4-6}$ As the current financial crisis represents the worst macroeconomic shock since the Great Depression, ${ }^{7}$ and government-introduced austerity measures are only aggravating an already grave situation (eg, in the third quarter of 2007 the unemployment rate was roughly $8.1 \%$, meanwhile by the same quarter of 2011 it had increased to approximately $21.3 \%$ ), and investigating the association between economic downturn and mental health is more important than ever. ${ }^{8-14}$

The Organization for Economic Co-operation and Development countries all experienced the effects of the 2008 financial crisis, but the Spanish economy was one of the hardest hit and its citizens had to rapidly come to terms with its consequences. In this context, ${ }^{15-19}$ Spain provides a unique opportunity to analyse the impact on financial 
crisis has on the health of a population. Spanish data agrees with the association made between a financial crisis and mental health problems. ${ }^{20-25}$ Although psychotropic drugs are used to treat mental health disorders, little (and contradictory) evidence analyses the effects the 2008 economic downturn had on psychotropic drug consumption.

Barceló $e t a l^{26}$ concluded that the increase in psychotropic drug consumption post 2009, is significantly higher among those most likely to be unemployed and those who were consumers before 2009. Moreover, the use is usually higher for those whose probabilities of consuming other drugs or alcohol are lower (eg, women). ${ }^{27}$ Interestingly, Colell $e t a l^{28}$ do not find any changes in sporadic use of hypnotics/sedatives between 2005-2007 and 2009-2011 and while they find unemployed men have a higher probability of reporting sporadic use than employed men do, this is lower for unemployed women.

This paper analyses differences in psychotropic drug consumption (antidepressants and sedatives), among the Spanish population between 2006-2007 and 2011-2012 (ie, before and during the financial crisis) by considering two of the most important determinants of health inequalities: gender and employment status. ${ }^{29}$

\section{METHODS}

\section{Data setting}

We used the microdata from the face-to-face cross-sectional population-based Spanish National Health Survey
(SNHS) for two periods: 2006-2007 and 2011-2012. ${ }^{30} 31$ The SNHS is a stratified tri-stage sample design representative of the Spanish population. Our samples included individuals ( $>15$ years old) responding to both adult and household questionnaires $(\mathrm{n}=28954$ for 2006-2007 and $\mathrm{n}=20509$ for 2011-2012). The difference between the sample sizes is because the SNHS 2006-2007 increased its initial sample size in Aragón, Baleares, Cantabria, Galicia, Murcia and Navarra (six out of the 17 Spanish regions) to reach the specific goals of obtaining more accurate estimations for the smaller geographical areas in those regions (eg, NUTS4 or health areas). However, the SNHS 2011-2012 did not include those specific goals.

The response variables are consumption (or not) of antidepressants or sedatives, because in the SNHS questions related to mental health problems these are the only ones asked for.

The explanatory variables are: the year of the survey (ie, 2006-2007-prior to the economic downturn, and 2011-2012-during the financial crisis), gender and employment status.

Covariates are age, region of residence (autonomous communities), educational level, marital status, social class of the reference person, ${ }^{32}$ mental health problems (represented by whether the individual has suffered from depression, anxiety or other mental health disorders in the past 12 months), a mental health index (GHQ$12)^{33}$ and self-reported health outcome variables such as self-rated health, chronic diseases, smoking behaviour,

Table 1 Descriptive statistics*

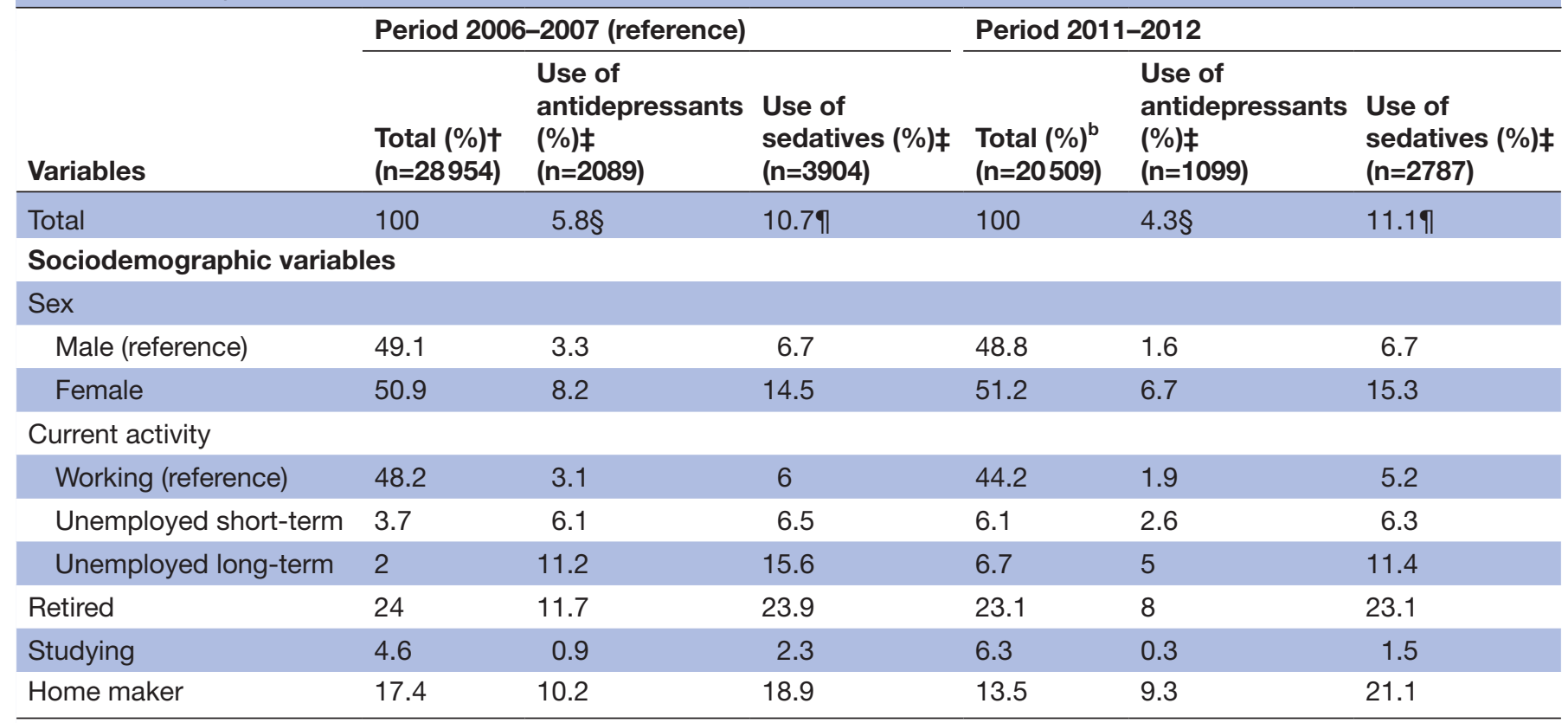

*Weighted distribution of the sample.

†For the categorical variables, data are \% in the category. The 2006-2007 survey increased its sample size in some regions to obtain more accurate estimations for smaller geographical areas (eg, NUTS4 or health areas).

$\ddagger$ For the categorical variables, data are \% of individuals using drugs for each case.

$\S \mathrm{P}<0.01$.

१P=0.735. 
Table 2 Mixed logistic estimations of the use of antidepressants and sedatives*

\begin{tabular}{|c|c|c|c|c|}
\hline & \multicolumn{2}{|l|}{ Antidepressants } & \multicolumn{2}{|l|}{ Sedatives } \\
\hline & $\operatorname{Exp}(\beta)(95 \% \mathrm{Cl})$ & P value & $\operatorname{Exp}(\beta)(95 \% \mathrm{Cl})$ & $P$ value \\
\hline \multicolumn{5}{|l|}{ Year (2006-2007) } \\
\hline \multicolumn{5}{|l|}{ Sex (male) } \\
\hline Female & 1.38 (1.19 to 1.61$)$ & $P<0.01$ & 1.48 (1.33 to 1.65$)$ & $\mathrm{P}<0.01$ \\
\hline \multicolumn{5}{|l|}{ Current activity (working) } \\
\hline Unemployed short-term & $1.14(0.81$ to 1.60$)$ & $\mathrm{P}=0.222$ & 0.71 (0.53 to 0.96$)$ & $P=0.134$ \\
\hline Unemployed long-term & 1.58 (1.09 to 2.28$)$ & $P<0.01$ & 1.25 (0.92 to 1.70$)$ & $P=0.074$ \\
\hline Retired & $1.44(1.21$ to 1.71$)$ & $P<0.01$ & 1.43 (1.25 to 1.63$)$ & $P<0.01$ \\
\hline Studying & $0.45(0.23$ to 0.89$)$ & $P=0.010$ & 0.59 (0.38 to 0.90$)$ & $P<0.01$ \\
\hline Home maker & 1.16 (0.98 to 1.37$)$ & $P=0.041$ & 1.35 (1.19 to 1.53$)$ & $P<0.01$ \\
\hline \multicolumn{5}{|l|}{ Interactions $†$} \\
\hline Activity*year (2) & $0.48(0.24$ to 0.95$)$ & $P=0.017$ & $0.72(0.45$ to 1.15$)$ & $P=0.084$ \\
\hline Activity*year (3) & $0.63(0.43$ to 0.95$)$ & $P=0.013$ & 0.78 (0.63 to 0.97$)$ & $P=0.011$ \\
\hline Activity*year (4) & 0.82 (0.10 to 6.83$)$ & $P=0.427$ & 0.76 (0.29 to 1.95$)$ & $P=0.283$ \\
\hline Activity $^{*}$ year (5) & 0.47 (0.10 to 2.09$)$ & $P=0.159$ & 0.57 (0.28 to 1.17$)$ & $P=0.064$ \\
\hline 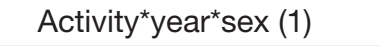 & 1.64 (0.55 to 4.90$)$ & $P=0.186$ & 1.34 (0.72 to 2.50$)$ & $P=0.179$ \\
\hline Activity $^{*}$ year $^{*} \operatorname{sex}(2)$ & $1.30(0.65$ to 2.60$)$ & $P=0.229$ & 1.46 (0.93 to 2.29$)$ & $P=0.052$ \\
\hline Activity*year*sex (3) & 1.56 (1.01 to 2.42$)$ & $P=0.023$ & 1.27 (0.99 to 1.63$)$ & $P=0.029$ \\
\hline Activity*year*sex (4) & 0.67 (0.06 to 7.94$)$ & $P=0.377$ & 1.02 (0.36 to 2.93$)$ & $P=0.483$ \\
\hline
\end{tabular}

*Global statistical results of variables of interest from the model adjusted for individual characteristics: sociodemographic variables (age, region of residence, level of education, marital status and social class) as well as subjective health variables (depression, mental health index, self-assessed health, chronic diseases, smoking, hours of sleep, body mass index, physical activity and medical visits).

†ln table 1, the variables of reference are shown.

sleeping hours, body mass index,${ }^{34}$ physical activity in the workplace and medical visits during the past year. For further information, see the appendices material (supplementary appendix A).

Finally, we include interactions between time period and gender, time period and employment status and between gender, time period and employment status.

\section{Patient and public involvement}

Patients and or public were not involved in this research.

\section{Statistical methods}

We specify random effects logistic regressions. In mixed model terminology, we allow the intercept to be random effect so it will be different for the various levels considered, that is, year, autonomous community and the interaction between year and autonomous community. We allowed heterogeneity at the level of autonomous community, thus capturing (unobserved) variables not already included in the model which could explain the probability of consuming psychotropic drugs. With the interaction with year, we allowed for this heterogeneity to vary along time because allowing random effects for year is equivalent to including a non-linear trend in the model.

For random effects at the autonomous community level, we assume that they are identical and independent of Gaussian random variables with constant variance. ${ }^{35} 36$ Random effects for year and interaction are modelled by a random walk of order 1 (ie, independent increments) for the Gaussian random effects vector. ${ }^{37}$

As the Bayesian estimation provides greater flexibility (a consequence of its hierarchical strategy), we chose to do the analyses using a Bayesian framework. In summary, the initial uncertainty about the effect measures (ie, ORs) and on extent of their variation, was first expressed through prior distributions. Next, we combined prior distributions with the so-called likelihood (ie, the current data), to obtain posterior distribution for the quantities of interest (again, ORs) and then we summarised the posterior distributions by point estimates and credible intervals (analogous to the classical CIs. A small modification in the standard priors (eg, increasing their precision) can imply very different inferences. That is why we need robust priors such as penalising complexity priors, 


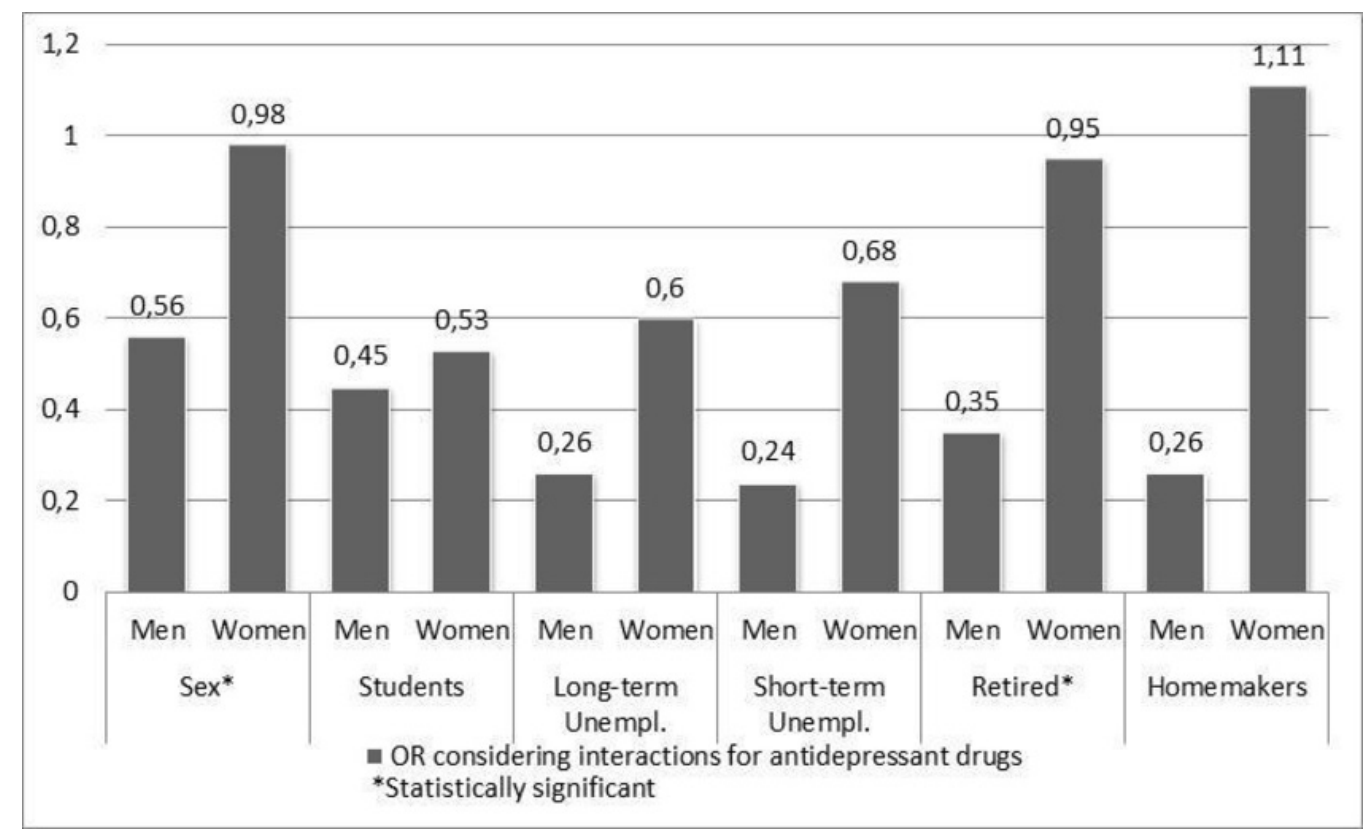

Figure 1 The risk of consuming antidepressant drugs in 2011-2012 compared with 2006-2007.

which are invariant to re-parameterisations and always provide the same inferences. ${ }^{38}$ One of the advantages of Bayesian analyses (with respect to the classical (or frequentist) analyses) is that it is the most suitable for accounting for model uncertainty, both in the parameters and in the specification of the models. Furthermore, only with Bayesian approach is it possible to model variability with relatively sparse data and it is also easier to specify more complex scenarios. Here we followed the integrated nested laplace approximation (INLA) approach, ${ }^{39}$ within a (pure) Bayesian framework.

The sampling weights (corrected for non-response and improved through ratio and calibration techniques) were used in the population estimations. All analyses are carried out with the free software $\mathrm{R},{ }^{40}$ available through the INLA library. ${ }^{35} 39$

\section{RESULTS}

Table 1 shows the descriptive characteristics of the two samples (SNHS 2006-2007 and SNHS 2011-2012) according to the consumption of antidepressants and sedatives for the variables of interest (see online supplementary appendix $\mathrm{B}$ of the appendices material available online for more in-depth information). In the total sample in SNHS 2006-2007 (49.1\% men), 5.8\% take antidepressants and $10.7 \%$ sedatives. In SNHS 2011-2012 ( $48.8 \%$ men), $4.3 \%$ consume antidepressants and $11.1 \%$ sedatives.

Table 2 shows the results of the mixed models of the variables of interest for antidepressants and sedatives. The results from the mixed logistic estimations without any year interactions concerning adult's mental health are available on request. Also, in this case, the adjusted OR of the year of the survey was not significant for antidepressant consumption or sedative use.

\section{Antidepressant consumption}

Table 2 shows that the year of the survey (which indicates the period of the economic downturn) is not significant, indicating that the financial crisis did not significantly change the probability of taking antidepressant drugs $(\mathrm{OR}=0.56,95 \%$ CI 0.18 to 2.53$)$. Using the results in table 2, we compute the OR by considering the interactions of the variables of interest (see figure 1). Then, we observe that, in general, the probability of consuming antidepressants among men and women decreases and is more marked in men, but differs depending on employment status (above all for short-term unemployed). For retired individuals, we find significant differences because, although women's risk of consuming psychotropic drugs does not change between 2006 and 2011, the risk for men drops dramatically. However, for the student group, risk of consumption reduces equally for both genders and so we cannot observe any differences between them in 2011. In the home maker's group (although $96.6 \%$ are women) this is where the biggest differences between men and women can be found because it is the only group where the risk of consuming antidepressants increases for women but drops sharply for men.

\section{Sedative consumption}

Table 2 shows that the year of the survey is not statistically significant and that the crisis has not significantly changed the likelihood of taking sedatives $(\mathrm{OR}=1.21,95 \%$ CI 0.26 to 5.49). Using the results in table 2 , we compute the OR by considering the interactions of the variables of interest (see figure 2). Again, we observe larger differences between women and men when employment status and 2011-2012 are considered. In the case of individuals in short-term unemployment, both men and women show that between 2006-2007 and 2011-2012 there was an increase in the risk of using sedatives, however, this 


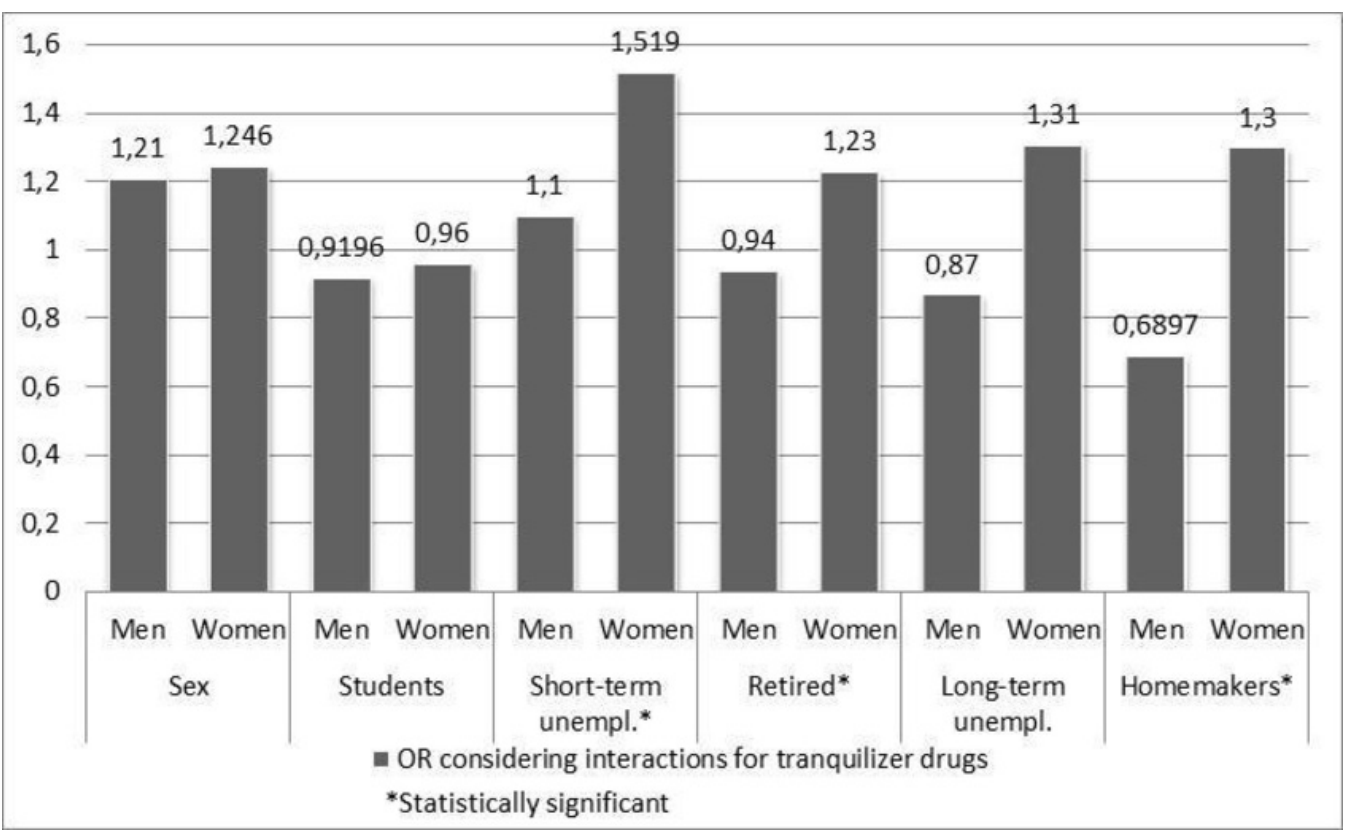

Figure 2 The risk of consuming sedative drugs in 2011-2012 compared with 2006-2007.

increase is higher for women than men. Nevertheless, although this group is where we find the biggest increase in the risk for women, it also contains the only status group where there is an increase in risk for men as well. For the long-term unemployed, however, the differences between both groups widen between 2006-2007 and 2011-2012, that is, women increase their risk of using sedatives, whereas men decrease that risk. The trend for retired individuals and home makers is not unlike the long-term unemployed, whereas for students, both groups reduce the risk of consuming sedatives between 2006-2007 and 2011-2012 and no changes are observed in the differences between the two groups in 2011.

The results from the mixed logistic estimations of the covariates are provided in the appendices material (see online supplementary appendix $\mathrm{C}$ ).

\section{DISCUSSION}

While the current financial crisis has not statistically changed the risk of using psychotropic drugs, our results do indicate that women in situations of long-term unemployment, retirement or home-making, seem to be at greater risk than men of using psychotropic drugs during this financial crisis. Results are adjusted by mental health status, presence of relevant mental health disorders and other health conditions associated with mental health status.

Some possible explanations are that during financial crisis women intensify their work to compensate for the losses in household income ${ }^{41}$ and their mental health deteriorates. In addition, it has been shown that some of the most serious and common situations created by the crisis in question, such as evictions, affect women's mental health more than men's. ${ }^{42}$ Likewise, women in Spain occupy positions inferior to men in the socio-labour sphere and, furthermore, the crisis has had an impact on the informal sectors of the economy which are occupied mostly by women. ${ }^{43}$

Cost and financial stress may reduce access to health and pharmaceutical services, as vulnerable populations or those who are financially better off increased the use of psychotropic drugs. Regarding the access to health services, the waiting time is found an important barrier for those who are limited in their daily activities by a chronic physical or mental health problem or disability, and in Spain the waiting time has sharply increased during the financial crisis. ${ }^{44}$

Like our study, Colell et $a l^{28}$ did not find significant changes in the sporadic use of hypnotics/sedatives for men or women (regardless of employment status) before and during a financial crisis either, nor did Nicieza-García et $a l^{45}$ confirm that the rise in psychotropic medication consumption in the region of Asturias was a result of the financial crisis. However, our results differ from other similar studies. For example, in the case of Pérez-Romero $e t a l,{ }^{46}$ using SNHS data they establish that for both men and women the use of these drugs increased during the financial crisis. However, they analyse antidepressant and sedative consumption together and only for employees.

To explain the differences found in the literature, it is important to consider that our analysis is the first to treat antidepressants and sedatives separately. While the unexpected decrease in antidepressant use could be because of a misclassification problem or changes in diagnosis and treatment practices, the existing literature can also be misleading because, unlike our study, the two drugs are not treated separately. Furthermore, while our results also show that the financial crisis is not associated with psychotropic drug use, we must consider that we are using data reported by individuals and so our response 
variables may be influenced by misreporting (or under-reporting) as the result of the stigma ${ }^{47}$ often associated with mental health issues and substance abuse. Parry et $a t^{48}$ studied the validity of responses from those using psychotropic drugs and observed that about $29 \%$ of males and $18 \%$ of females give invalid responses. They attribute the under-reported answers among men (compared with the higher rates of consumption by females, especially in the case of sedatives) to the negative stigma men associate with these drugs.

Our study has some limitations. Even though we use two large samples of individual-level data, we use cross-sectional data which does not allow us to conclude direct relationships between the financial crisis and psychotropic drug use. Besides, even though self-reported measures of health are strongly correlated with mortality, ${ }^{49}$ there could be a reporting bias affecting individuals' self-reported responses. Moreover, the (seemingly) marginal effect the financial crisis has had on mental health problems and psychotropic drug use could be explained by a reluctance to respond to (for some) sensitive questions in a personal face-to-face interview.

Sample size (more than 40000 representative interviews in Spain before and during the financial crisis), is one of the fundamental strengths of this study and provides meaningful results to discern the effects economic recessions have on mental health. Our key contribution is to have identified (using gender and unemployment status) the groups most vulnerable to a financial crisis. Policy-makers must take these groups into consideration (through research efforts, along with healthcare and social interventions) when planning strategies and implementing policy to mitigate health inequities.

Future lines of research could focus on determining the role new medications are currently playing, as their development and rapid spread is quickly displacing the conventional psychotropic drug market.

\section{Author affiliations}

${ }^{1}$ Research Group on Statistics, Econometrics and Health (GRECS), Universitat de Girona, Girona, Spain

${ }^{2}$ CIBER of Epidemiology and Public Health, CIBER of Epidemiology and Public Health (CIBERESP), Madrid, Spain

${ }^{3}$ Escuela Andaluza de Salud Publica, EASP, Granada, Spain

${ }^{4}$ Center for Research in Occupational Health (CiSAL), Experimental and Health Sciences, University Pompeu Fabra, Barcelona, Spain

${ }^{5}$ Center for Research in Occupational Health (CiSAL), Experimental and Health Sciences, IMIM (Hospital del Mar Medical Research Institute) Parc de Salut Mar, Barcelona, Spain

${ }^{6}$ Observatorio de Salud y Medio Ambiente de Andalucía (OSMAN), Escuela Andaluza de Salud Pública (EASP), Granada, Spain

Acknowledgements We appreciate the comments of the attendees at the XXXIV Reunión Científica de la Sociedad Española de Epidemiología (SEE) 2016, on September from 14 to 16, 2016, in Sevilla, Spain and at the Third EuHEA PhD student-supervisor and early career researcher conference, from 7 to 9 September 2016, in Barcelona, Spain. We appreciate the comments from four anonymous reviewers, which have undoubtedly helped to improve this work.

Contributors EA had the original idea for the paper. EA, MS and AC-L designed the study. The bibliographical search and the writing of the introduction were by EA, AC-L, CS, GR and LSS. The choice of methods and statistical analysis was performed by MS. EA, CS, LSS, GR and AC-L built the tables and figures. All authors wrote the results and the discussion. The writing and final editing was done by EA, MS, AC-L, AD and CS. All authors reviewed and approved the manuscript.

Funding This work was partly funded by the CIBER of Epidemiology and Public Health (CIBERESP) through the strategic subprogram 'Crisis and Health', by the Catalan Government Project, AGAUR, 'Compositional and Spatial Analysis' (COSDA), 2014SGR551, and by the University of Girona through the Research Grant to Improve the Scientific Productivity of the Research Groups of the University of Girona 2016-2018 (MPCUdG2016/69). The first author carried out this research with the support of the Short Term Grant Abroad for PhD European, CIBER of Epidemiology and Public Health (CIBERESP), Spain, the support of the Mobility Fellowship among intra-groups of CIBERESP, CIBER of Epidemiology and Public Health (CIBERESP), Spain, and was also beneficiary of the Grant for Pre-doctoral Studies from the University of Girona (BR 4/2013), Girona, Spain.

Competing interests None declared.

Patient consent for publication Not required.

Provenance and peer review Not commissioned; externally peer reviewed.

Data sharing statement We used Spanish Health Survey data in all cases. Public and freely accessible at: http://www.msssi.gob.es/estadEstudios/estadisticas/ encuestaNacional/encuesta2006.htm and http://www.msssi.gob.es/estadEstudios/ estadisticas/encuestaNacional/encuesta2011.htm (both in Spanish).

Open access This is an open access article distributed in accordance with the Creative Commons Attribution Non Commercial (CC BY-NC 4.0) license, which permits others to distribute, remix, adapt, build upon this work non-commercially, and license their derivative works on different terms, provided the original work is properly cited, appropriate credit is given, any changes made indicated, and the use is non-commercial. See: http://creativecommons.org/licenses/by-nc/4.0/.

\section{REFERENCES}

1. Ruhm CJ. Are recessions good for your health? Q J Econ 2000;115:617-50.

2. Marmot MG, Bell R. How will the financial crisis affect health? BMJ 2009;338:858-60.

3. Bezruchka S. The effect of economic recession on population health. CMAJ 2009;181:281-5.

4. Catalano R, Goldman-Mellor S, Saxton K, et al. The health effects of economic decline. Annu Rev Public Health 2011;32:431-50.

5. Brenner $\mathrm{MH}$, Mooney A. Unemployment and health in the context of economic change. Soc Sci Med 1983;17:1125-38.

6. Goldman-Mellor SJ, Saxton KB, Catalano RC. Economic contraction and mental health: a review of the evidence, 1990-2009. International Journal of Mental Health 2010;39:6-31.

7. Jenkins SP, Brandolini A, Micklewright J, et al. The great recession and the distribution of household income: Oxford University Press, 2012.

8. Uutela A. Economic crisis and mental health. Curr Opin Psychiatry 2010;23:127-30.

9. Zivin K, Paczkowski M, Galea S. Economic downturns and population mental health: research findings, gaps, challenges and priorities. Psychol Med 2011;41:1343-8.

10. Mclnerney M, Mellor JM, Nicholas LH. Recession depression: mental health effects of the 2008 stock market crash. $J$ Health Econ 2013;32:1090-104.

11. Gili M, García Campayo J, Roca M. [Economic crisis and mental health. SESPAS report 2014]. Gac Sanit 2014;28:104-8.

12. McKenzie SK, Imlach Gunasekara F, Richardson K, et al. Do changes in socioeconomic factors lead to changes in mental health? Findings from three waves of a population based panel study. J Epidemiol Community Health 2014;68:253-60.

13. Katikireddi SV, Niedzwiedz CL, Popham F. Trends in population mental health before and after the 2008 recession: a repeat crosssectional analysis of the 1991-2010 health surveys of England. BMJ Open 2012;2:5:e001790.

14. Barr B, Kinderman $P$, Whitehead M. Trends in mental health inequalities in England during a period of recession, austerity and welfare reform 2004 to 2013. Soc Sci Med 2015;147:324-31.

15. National Statistics Institute (INE). Active population survey. 2016. Available at http://www.ine.es (Accessed 15 Jan 2016).

16. Eurostat. 2016. Available at: http://ec.europa.eu/eurostat. (Accessed 30 Jan 2016)

17. de la Rica S, Rebollo-Sanz YF. Gender differentials in unemployment ins and outs during the great recession in Spain. Fedea, Madrid: Estudios sobre la economía Española, 2015. 
18. Bentolila S, Cahuc P, Dolado JJ, et al. Two-tier labour markets in the great recession: France Versus Spain. Econ J 2012;122:F15 5-F187.

19. National Statistics Institute (INE). Foreclosure Statistics. 2016. Available at http://www.ine.es (Accessed 15 Jan 2016).

20. Gili M, Roca M, Basu S, et al. The mental health risks of economic crisis in Spain: evidence from primary care centres, 2006 and 2010. Eur J Public Health 2013;23:103-8.

21. Urbanos-Garrido RM, Lopez-Valcarcel BG. The influence of the economic crisis on the association between unemployment and health: an empirical analysis for Spain. Eur $J$ Health Econ 2015;16:175-84.

22. Artazcoz L, Benach J, Borrell C, et al. Unemployment and mental health: understanding the interactions among gender, family roles, and social class. Am J Public Health 2004:94:82-8.

23. Pascual N, Rodríguez I. Effects of unemployment on self-assessed health and mental health: empirical evidence for Catalonia (20062012). Masters Project: Masters in Health Economics and Policy, Barcelona Graduate School of Economics, 2013.

24. Bacigalupe A, Esnaola S, Martín U. The impact of the Great Recession on mental health and its inequalities: the case of a Southern European region, 1997-2013. Int J Equity Health 2016;15:17.

25. Bartoll X, Palència L, Malmusi D, et al. The evolution of mental health in Spain during the economic crisis. Eur J Public Health 2014;24:415-8.

26. Barceló MA, Coll-Negre M, Coll-de-Tuero G, et al. Effects of the financial crisis on psychotropic drug consumption in a cohort from a semi-urban region in catalonia, Spain. PLoS One 2016;11:e0148594.

27. Mellinger GD, Balter MB, Manheimer DI. Patterns of psychotherapeutic drug use among adults in San Francisco. Arch Gen Psychiatry 1971;25:385-94.

28. Colell E, Sánchez-Niubò A, Delclos GL, et al. Economic crisis and changes in drug use in the Spanish economically active population. Addiction 2015;110:1129-37.

29. Catalan Health System Observatory. Economic inequalities in health and the utilization of public health services in the population of Catalonia [in Catalan]. Barcelona: Agency for Health Quality and Assessment of Catalonia (AQuAS): Department of Health. Catalan Government, 2017.

30. Ministry of Health, Social Services and Equity: National Health Survey in Spain 2006 and 2011. Householder questionnaire and adult questionnaire. $2013 \mathrm{http} / / / w w w . m s s s i . g o b . e s / e s t a d E s t u d i o s /$ estadisticas/encuestaNacional/encuesta2006.htm

31. (EHIS). European Health Interview Survey (EHIS). $2016 \mathrm{http}: / / \mathrm{ec}$. europa.eu/eurostat/c/portal/layout?p_I_id=203688\&p_v_Is_g_id=0 (Accessed 15 Apr 2016).
32. Chilet-Rosell E, Álvarez-Dardet C, Domingo-Salvany A. [Use of Spanish proposals for measuring social class in health sciences] Gac Sanit 2012;26:566-9.

33. Goldberg D. Mental health priorities in a primary care setting. Ann N Y Acad Sci 1978;310:65-8.

34. World Health Organization. Body mass classification. $2016 \mathrm{http}: / /$ apps.who.int/bmi/index.jsp?introPage=intro_3.html (Accessed 15 Ap 2016).

35. R-INLA project. Bayesian computing with INLA. $2016 \mathrm{http}: / / \mathrm{www}$. r-inla.org/ (Accessed 25 May 2016)

36. R INLA project. Independent random noise model. $2016 \mathrm{http} / / / \mathrm{www}$. math.ntnu.no/inla/r-inla.org/doc/latent/rw1.pdf (Accessed 25 May 2016).

37. R INLA project. Random walk model of order 1. $2016 \mathrm{http} / / / \mathrm{www}$. math.ntnu.no/inla/r-inla.org/doc/latent/rw1.pdf (Accessed 25 May 2016).

38. Simpson DP, Rue H, Martins TG, et al. Penalising model component complexity: a principled. practical approach to constructing priors. arxiv 2015;1403.

39. Rue H, Martino S, Chopin N. Approximate bayesian inference for latent gaussian models by using integrated nested laplace approximations. Journal of the Royal Statistical Society: Series $B$ 2009;71:319-92.

40. R Core Team.: R: A language and environment for statistical computing. R Vienna, Austria: Foundation for Statistical Computing, 2015. Available at. (Accessed 25 May 2016).

41. Floro MS. Economic restructuring, gender and the allocation of time. World Dev 1995;23:1913-29.

42. Bolívar Muñoz J, Bernal Solano M, Mateo Rodríguez I, et al. [The health of adults undergoing an eviction process]. Gac Sanit 2016;30:4-10.

43. Women and men in Spain in 2010. Instituto Nacional de Estadística. 2010.

44. Healthcare Services. Impacts of the crisis on access to healthcare services in the EU. Eurofound, Dublin, 2013.

45. Nicieza-García ML, Alonso-Lorenzo JC, Suárez-Gil P, et al. Efecto de la crisis económica sobre el consumo de psicofármacos en Asturias. Gac Sanit 2016;30:464-7.

46. Pérez-Romero S, Gascón-Cánovas JJ, de la Cruz-Sánchez E, et al Recesión económica (2006-2012) y cambios en el estado de salud de la población española. Salud Pública de México 2016;58:41-8.

47. Corrigan PW, Watson AC. Understanding the impact of stigma on people with mental illness. World Psychiatry 2002;1:15-20.

48. Parry HJ, Balter MB, Cisin IH. Primary levels of underreporting psychotropic drug use. Public Opin Q 1970;34:582-92.

49. Kaplan GA, Camacho T. Perceived health and mortality: a nine-year follow-up of the human population laboratory cohort. Am J Epidemiol 1983;117:292-304. 